\title{
Has Duesberg a right of reply?
}

\section{Dr Peter Duesberg, the virologist-turned-campaigner, is wrongly using tendentious arguments to confuse understanding of AIDS and those in danger of contracting the disease. He should stop.}

WHAT is to be thought of a science journal that publishes attacks on the opinions of a scientist, but which never (or hardly ever) publishes his replies? On the face of things, this is a serious breach of journalistic ethics - and it would be legally prevented by the legislation on the press perpetually being considered by the British House of Commons. Yet that is how Nature has behaved to Dr Peter Duesberg, the virologist from Berkeley who is identified with the view that HIV does not cause AIDS. How can such intolerance be justified?

What follows is an explanation. But first, an essential part of the tale is that Duesberg is a molecular virologist of distinction; his last major publication in Nature $\mathbf{( 3 0 4}, \mathbf{2 1 9}$; 1983) was a classic of its kind. He is also a person of intelligence and good humour. Moreover, there are elements in his position on the causation of AIDS that are not nearly as perverse as they are often represented.

Early on, Duesberg raised some cogent questions. For example, why, if HIV is an infectious agent and also the cause of AIDS, is it so difficult to recover virus from the particular T cells (CD4 cells) that are supposedly its targets? And why do morbidity and mortality among those with haemophilia infected by contaminated blood products appear to be so much less than among those who have acquired HIV by, say, homosexual sexual intercourse?

These questions were proper questions, if not the only ones that may legitimately be asked about AIDS as a disease. Why, for example, is otherwise rare Kaposi's sarcoma so commonly one of the consequences of infection by HIV (and why is it uncommon among infected haemophiliacs)? Why is diarrhoea often one of the first symptoms of overt AIDS, and what can be done to prevent its debilitating effects? Why is the "incubation period" so long and variable? A full understanding of the pathogenesis of AIDS would answer all these questions.

So why scorn Duesberg's demand of the research community for answers to his proper questions? Part of the explanation is that Duesberg has not been asking questions, or raising questions he believes should be answered, but has been making demands and implying (but sometimes saying outright) to colleagues, "Unless you can answer this, and right now, your belief that HIV causes AIDS is wrong". It is as if a person were to have told Schrödinger in 1926, "Unless you can calculate the spectrum of lithium hydride, quantum mechanics is a pack of lies". (Interestingly, that deceptively simple question is only now being answered.)

Unanswerable rhetorical questions are the stock-in-trade of undergraduate debating societies. In the grown-up world, the obligation to answer even well-posed questions is a function of circumstances. True, good theories (pace Popper) are falsifiable theories, and a single falsification will bring a good theory crashing down. But unanswered questions are not falsifications; rather, they should be the stimulants of further research. Whether researchers divert effort from current preoccupations to answer other people's questions properly depends on their personal judgement of the cogency and relevance of the questions and even on the motives of the questioner.

Duesberg has forfeited the right to expect answers by his rhetorical technique. Questions left unanswered for more than about ten minutes he takes as further proof that HIV is not the cause of AIDS. Evidence that contradicts his alternative drug hypothesis is on the other hand brushed aside. Thus Duesberg's reply to A. J. Pinching's question why, if transfusions of Factor VIII are the true cause of AIDS among haemophiliacs, do patients uninfected by HIV never contract AIDS, is tantamount to an assertion that the patients must have been selected with bias or that the data must be false (see Nature 350, 10; 1991).

For what it is worth, Duesberg's remark about the difficulty of recovering virus from $\mathrm{T}$ cells is linked with the question of the incubation period; both will probably be answered by studies provoked by the recent discovery of large amounts of virus in the lymph nodes of infected people quite early in the incubation period (see Nature 362, $355-359 ; 1993$ ). The difference between the incidence of AIDS among haemophiliacs and homosexual men is more apparent than real (see, for example, C. Lee et al. Br. med. J. 303, 1093; 1991) and is accounted for by the difference of age distribution between the two groups. (The younger a person, the slower the progression to AIDS.) The rhetorical question why infected haemophiliacs rarely develop Kaposi's sarcoma is logically no more disconcerting than the question why this rare condition is so common among homosexual men with AIDS.

Rhetorical techniques such as these are only barely forgivable among otherwise friendly colleagues; people's patience with travesties of science is understandably thin. Duesberg has made his debating technique thoroughly intolerable by advertising his position to the AIDS community, thus giv- ing many infected people the belief that HIV infection is not in itself the calamity it is likely to prove.

Nature's most recent refusal of an intended publication by Duesberg was of his response to an article on the "drug hypothesis” by M. Ascher et al. (362, 103; 1993), which used data on a group of more than 1,000 men recruited in 1984 in San Francisco to show no correlation between the incidence of AIDS and previous drug-taking. The likelihood of developing AIDS was found to be 1.56 times as great among heavy drug-users as among those using them more moderately or not at all, while the chance of HIV infection was 1.43 times as great in the first group as in the second.

Duesberg's unpublished reply, on the basis of what is most charitably called a misreading of the text, asserts that the authors must have fabricated some of their data. He goes on to claim that the authors' argument supports his view, not theirs. He quarrels with an imagined failure to collect data on drug use after recruitment and claims that a two-year study cannot test the hypothesis of drug toxicity requiring ten years for its effects to become overt. (Readers seeking further information will find the essence of Duesberg's reply, provoked by a report by Ascher et al., in The Lancet 341, 958; 1993).

Interestingly, as a referee of his unpublished letter to Nature has pointed out, some of the most telling evidence against Duesberg's position arises from the recent Anglo-French study of the use of AZT as a prophylactic of AIDS in people infected by HIV (The Lancet 341, 889-990; 1993). The negative finding of that study is also, incidentally, evidence that AZT is not the danger-drug that Duesberg has claimed. There is no mention of that awkward circumstance in his intended reply to Ascher et al.

The truth is that a person's "right of reply" may conflict with a journal's obligations to its readers to provide them with authentic information. Whatever Duesberg's friends say, the right of reply must be modulated by its content.

Duesberg will not be alone in protesting that this is merely a recipe for suppressing challenges to received wisdom. So it can be. But Nature will not so use it. Instead, what Duesberg continues to say about the causation of AIDS will be reported in the general interest. When he offers a text for publication that can be authenticated, it will if possible be published - not least in the hope and expectation that his next offering will be an admission of recent error. John Maddox 